\title{
Applying collaborative cognitive load theory to computer-supported collaborative learning: towards a research agenda
}

\author{
Jeroen Janssen ${ }^{1}$ (D) Paul A. Kirschner ${ }^{2}$
}

Published online: 21 January 2020

(C) The Author(s) 2020

\begin{abstract}
Research on computer-supported collaborative learning (CSCL) has traditionally investigated how student-, group-, task-, and technological characteristics affect the processes and outcomes of collaboration. On the other hand, cognitive load theory has traditionally been used to study individual learning processes and to investigate instructional effects that are present during individual learning (e.g., expertise reversal effect). In this contribution we will argue that cognitive load theory can be applied to CSCL. By incorporating concepts such as collective working memory (i.e., individuals share the burden of information processing), mutual cognitive interdependence (i.e., individuals learn about each other's expertise and become dependent on their partners' expertise), and transaction costs (i.e., the burden placed on individuals working memory capacity when communicating and coordinating collaborative activities), collaborative cognitive load theory (CCLT) can be used to formulate testable hypotheses for pressing issues in CSCL research. The aim of this paper is to develop a research agenda to guide future CSCL research from a CCLT perspective. We highlight how variables associated with student-, group-, task-, and technological characteristics may be investigated using CCLT. We also address important steps CSCL research needs to make with respect to the measurement of variables and the methodologies used to analyze data.
\end{abstract}

Keywords Computer-supported collaborative learning · Cognitive load · Transactive activities $\cdot$ Collective working memory

Research on Computer-Supported Collaborative Learning (CSCL) has a long tradition. Since the 1990s, theorists, researchers, and practitioners have investigated the possible affordances provided by technological artefacts that can give rise to or enable collaboration at a distance between group members (Silverman 1995). This has led to a rich

Jeroen Janssen

j.j.h.m.janssen@uu.nl

1 Department of Education, Faculty of Social and Behavioural Sciences, Utrecht University, P.O. Box 80140, 3584 CS Utrecht, The Netherlands

2 Open University of The Netherlands, Heerlen, The Netherlands 
empirical knowledge base that, for example, demonstrates that collaboration scripts can support acquisition of domain-specific knowledge (Vogel et al. 2017) or that assigning functional roles to team members can support the effective implementation of collaborative learning processes (Strijbos et al. 2007). A recent meta-analysis by Chen et al. (2018) summarized the outcomes of three types (quasi-)experimental studies often carried out by CSCL researchers, namely studies that investigate the effects of (1) collaboration vs. individual learning in computer-supported learning settings, (2) the use of computers during collaboration, and (3) adding additional learning environments, tools, and scaffolds in CSCL. Their meta-analysis demonstrates that (1) collaboration itself, (2) computer use, and (3) learning environments, tools, and scaffolds all have significantly positive effects on students' knowledge acquisition during CSCL. What it also demonstrates is that different (and sometimes contradictory) theoretical perspectives abound in CSCL research. Furthermore, although Chen et al. demonstrated that, in general, collaboration, computer use, and learning environments all had medium to large effects on knowledge acquisition, considerable variance in the effect sizes could not be explained. In our contribution to this special issue we will argue that Collaborative Cognitive Load Theory (Kirschner et al. 2018) may be used to inspire CSCL studies that can be used to answer important research questions around the design, implementation, and effects of CSCL and can further elucidate the conditions that determine effective CSCL.

Kirschner et al. (2018) described how cognitive load theory (Sweller 1988) can be applied to (computer-supported) collaborative learning situations by expanding cognitive load theory to include concepts such as mutual cognitive interdependence, collective working memory, and transactive activities that elicit transaction costs. They refer to this expanded theory as Collaborative Cognitive Load Theory (CCLT). In this contribution, we will show how CCLT can be used to formulate hypotheses for current issues in CSCL research as well as instructional guidelines for the design of CSCL.

\section{Cognitive load theory}

Before explaining how cognitive load theory (CLT) can be applied to collaborative learning, we first briefly introduce CLT and explain its basic assumptions (i.e., human cognitive architecture) and concepts (i.e., intrinsic and extraneous load). Knowledge can be categorized in many different ways. CLT sees Geary's (2012) distinction between biologically primary and biologically secondary knowledge, which include skills and the knowledge produced by them, as most useful for educational purposes intended to lead to different types of instruction. In Geary's framework, humans have evolved to almost effortlessly and without explicit instruction acquire biologically primary knowledge due to (1) group support of the members of a community and (2) the evolutionary necessity of their acquisition (i.e., if the species member cannot naturally acquire this knowledge, (s)he will not survive long enough to procreate). In contrast, we humans have not evolved to acquire biologically secondary knowledge without intentionally designed effective learning environments. To acquire this knowledge, substantial effort and therefore proper support and guidance is required (i.e., instruction; Kirschner et al. 2006; Sweller et al. 2007).

What we know and how we learn is both shaped and limited by the architecture of our cognitive system and how it functions. How humans construct biologically secondary knowledge in their cognitive system is analogous to how evolution by natural selection 
Table 1 Natural information processing system principles (from Kirschner et al. 2018)

\begin{tabular}{|c|c|}
\hline Principle & Function \\
\hline Information store & $\begin{array}{l}\text { Primary and secondary knowledge and skills are stored in long term } \\
\text { memory }\end{array}$ \\
\hline Borrowing and reorganizing & $\begin{array}{l}\text { The knowledge store is mostly borrowed from other's knowledge } \\
\text { and is reorganised in a particular way }\end{array}$ \\
\hline Randomness as genesis & $\begin{array}{l}\text { When relevant knowledge is absent, required new/novel knowledge } \\
\text { is created by random generation-and-testing }\end{array}$ \\
\hline Narrow limits of change & $\begin{array}{l}\text { Limited capacity and duration of working memory processing } \\
\text { prevent rapid random changes of the store }\end{array}$ \\
\hline Environmental organising and linking & $\begin{array}{l}\text { Interacting with the environment requires signals that allow trans- } \\
\text { ferring organized information from long term memory to working } \\
\text { memory to carry out appropriate actions }\end{array}$ \\
\hline
\end{tabular}

processes information (Sweller and Sweller 2006). This architecture is described in five principles (see Table 1).

When learners receive novel information, there are two additive sources of cognitive load that are imposed on working memory (Sweller 2010). The combination of the two should not exceed the limits of the learners' working memory. Intrinsic load is based upon the inherent complexity of the information presented in a learning task and is defined in terms of the number of novel information elements in a task and the way in which these elements do or do not interact with each other. The more novel interacting elements, the more complex the task is; especially when time is an issue.

In addition, there may be interacting elements unrelated to the intrinsic complexity of the task. When this is the case, we speak of the imposition of extraneous load ${ }^{1}$ on working memory. This load can be controlled and varied by the instructional procedures that are used. Some procedures (e.g., discovery or inquiry learning) impose more unproductive load (cf. Kirschner et al. 2006) on working memory than others (e.g., worked examples, process worksheets, cf. Atkinson et al. 2000) and demand more time and mental effort on the task.

Finally, both intrinsic and extraneous cognitive load interact with each other as well as with the learner's level of expertise (Chen et al. 2016a, b). A learner with task-relevant prior knowledge in her/his long-term memory (i.e., an advanced learner) will experience lower cognitive load than a learner with little prior knowledge for that same task. On the other hand, learning will be impeded for an advanced learner (i.e., a learner with considerable prior knowledge or experience in the subject area) if (s)he is instructed in a way that combines new with redundant information (e.g., diagrams with integrated text; spatially contiguous materials, cf. Kalyuga et al. 1998). When this is the case, the embedded texts can/will interfere with the information already available in learners' long-term memory, increase the experienced cognitive load, and, thus, reduce their performance (i.e., expertise reversal effect; Chen et al. 2016a, b).

\footnotetext{
1 According to Kalyuga (2011, p. 1), "[I]n its traditional treatment, germane load is essentially indistinguishable from intrinsic load, and therefore this concept may be redundant ... the dual intrinsic/extraneous framework is sufficient and non-redundant and makes boundaries of the theory transparent. As such, germane load is not treated as an additive source of load here."
} 


\section{Applying cognitive load theory to (computer-supported) collaborative learning}

Collaborative learning refers to scenarios during which two or more students work together on a task that gives them a mutual learning goal (Johnson and Johnson 2009). Furthermore, to attain this mutual learning goal, students are encouraged or required to share the effort that is needed to accomplish the task (Teasley and Roschelle 1993). During CSCL, computer support is offered to group members to facilitate the process of working together on the learning task. In short, CSCL is about learning collaboratively with the support of computers and computer networks.

More specifically, support tools incorporated in CSCL-environments can be considered instructional measures that support learners in reaching the learning goals. Kirschner and Erkens (2013) refer to three types of measures: interactive, representational, and guiding. Interactive measures are aimed at supporting students during the necessary interaction and communication processes to successfully complete the group task (e.g., Hadwin et al. 2018; Kreijns et al. 2007). The representational measures available in some CSCL-environments support students during the often difficult process of structuring and organizing task-related information (e.g., Gijlers and De Jong 2013; Erkens et al. 2005; Kollöffel et al. 2011; Van Amelsvoort et al. 2007) or help them acquire information about collaborative processes such as group member participation or agreement with group members' contributions (e.g., Janssen and Bodemer 2013; Janssen et al. 2007; Schnaubert and Bodemer 2019). Finally, collaboration support measures are meant to guide students during the collaborative process. They give directions and scaffolds to students to help them determine which next collaborative step may best be taken, for example by offering students collaboration scripts (e.g., Hadwin et al. 2018; Vogel et al. 2017) or peer feedback (e.g., Xiao and Lucking 2008). To better understand and study why these interactive, representational, and collaboration support measures are effective and under which conditions, cognitive load theory can be very useful (cf. Janssen et al. 2010; Kirschner et al. 2009a). Below, we explain how cognitive load theory may be applied to CSCL by incorporating concepts such as collective working memory, mutual cognitive interdependence, and transaction costs (Kirschner et al. 2009a,2018). We introduce these concepts by examining the advantages and disadvantages of collaboration from a cognitive load perspective.

\section{Advantages of collaboration: collective working memory}

Chen et al.'s (2018) recent meta-analysis demonstrated-amongst other things-a significant positive effect of collaborative learning versus individual learning on knowledge achievement $(g=+0.42)$, skill acquisition $(g=+0.64)$, and student perceptions $(g=+0.38)$ in computer-based settings. Similar positive effects of collaboration have been documented in more traditional, face-to-face learning situations (Capar and Tarim 2015; Kyndt et al. 2013; Warfa 2016). Thus, it seems that the advantages of (computersupported) collaborative learning are well documented. Because meta-analyses such as those conducted by Chen et al. focus on the outcomes of collaborative learning, they cannot explain which learning processes are responsible for these positive effects.

Research has shown that positive interdependence is an important condition for effective and efficient collaborative learning (Asterhan and Schwartz 2016; Johnson and Johnson 1999; Lou et al. 1996). Positive interdependence exists during collaboration when students require the input and effort of all their group members to complete the group task they 
have been assigned. This can, for example, be accomplished by assigning students a complex task that they cannot solve on their own (i.e., goal interdependence, cf. Johnson et al. 1989) or by giving each student information necessary to carry out the task that is complementary to the information held by their group members (i.e., resource interdependence, cf. Buchs and Butera 2009; Buchs et al. 2004). When students experience positive interdependence, they realize they cannot succeed unless the other group members succeed and this in turn stimulates them to engage in high quality interaction with their group members (cf. Roseth et al. 2008).

But what is high quality interaction? When students engage in high quality interaction, they are for example sharing information with their fellow group members. When this happens, the individual group members as well as the group as a whole develop shared understanding and an awareness of which group member possesses what knowledge and expertise (Kirschner et al. 2011a, b). This has been referred to as transactive memory (Wegner 1987, 1995). Although Wegner's theory on transactive memory was developed for non-instructional context, it has also been successfully applied to instructional contexts (e.g., Kirschner et al. 2009a; Noroozic et al. 2013). Groups may develop transactive memory systems when individual group members develop knowledge about the expertise of the other group members. When individual group members combine this knowledge about their peers' expertise with their own knowledge, they can devise ways to share and processes information more efficiently according to the expertise of each group member (Hollingshead 2001; Noroozi et al. 2013; Popov et al. 2017). A transactive memory system can be considered a prerequisite for effective collaborative discussions and high quality interaction between group members. During transactive discussions group members try to consciously refer to the knowledge and expertise of the other group members, and try to build upon this knowledge and expertise of their partners. In a now classic experiment, Teasley (1997) demonstrated that when dyads engaged in such transactive discussions, this contributed to their learning achievements. Similar results were obtained by Barron (2003). Her study demonstrated that when group members connected their ideas and contributions to the preceding remarks made by the other group members, this facilitated their learning. In sum, when group members become aware of the knowledge and expertise of their fellow group members and engage in transactive discussions leading to effective and efficient learning processes. But how can these findings be explained from CCLT?

CCLT considers groups of collaborative learners as information processing systems (cf. De Dreu et al. 2008; Tindale and Kameda 2000). Above, we described how CLT is concerned with ways to manage individual working memory load and to optimize information processing in individual learning situations. In contrast, CCLT emphasizes that when individuals experience positive interdependence (Johnson and Johnson 1999, 2009), they may pool the cognitive resources of their working memories to allow for a greater information processing capacity compared to individual learning situations (Kirschner et al. 2009a; Kirschner et al. 2011a). In this respect Kirschner et al. (2009a) referred to this effect as the distribution advantage of collaborative learning: collaborating students may need to invest less cognitive effort during the learning process compared to students studying individually (Kirschner et al. 2018). This is because, in contrast to students studying individually, collaborating students may divide the intrinsic load caused by the task's interacting information elements over the multiple working memories available in the group. This, in essence, increases the cognitive resources available to an individual student: by sharing the burden of information processing with other group members, a collaborating student will need to devote fewer cognitive resources to seeking information and problem solving, compared to students studying individually (Kirschner et al. 2018; Retnowati et al. 2017). 
Several mechanisms may account for this distribution advantage. First, collaborating groups experience a distribution advantage because not all group members need to possess all of the required information to carry out the collaborative task (Wegner 1995). When group members sufficiently engage in transactive discussion, they are able to share the information elements of the task and thus the demands placed on individual working memory are reduced (Janssen et al. 2010): several working memories work in unison and share the demands placed on the working memory capacity of the individual. Second, collaborating students may engage in a shared division of labor: when working on a collaborative task, students may realize that the task consists of several subtasks that can be performed by individual group members. When group members divide these tasks, the effort required from each individual student is lowered, leaving additional room for deeper processing of the learning material. Finally, the mutual cognitive interdependence principle (cf. Kirschner et al. 2018) accounts for the distribution advantage by explaining that during collaboration group members acquire knowledge about each other's areas of expertise and knowledge and become dependent on one another for generating and acquiring knowledge (Hollingshead 2001). Through transactive discussions, group members start to acquire information previously held by their partners. In essence, group members make use of their partners' memories to acquire relevant information (Wegner 1987). In fact, they depend and rely on both their own memories and their partners' memories to achieve their goals.

The distribution advantage hypothesis posits that when groups have complementary knowledge and expertise (i.e., when a group is heterogeneous), collaborative learning will be more effective and efficient. This is corroborated in studies comparing heterogeneous groups versus homogeneous groups. For example, Zhang et al. (2016) found that in heterogeneous groups, students' learning achievements were greater than in homogeneous groups. This finding was most pronounced for students with relatively little prior knowledge. Thus, when group members are able to divide the cognitive resources required to carry out the task with their group members and engage in transactive discussion to ensure knowledge and expertise is exchanged within the group, this positively impacts the effectiveness of collaborative learning.

\section{Disadvantages of collaboration: transaction costs}

Anyone who has ever worked in a group will surely acknowledge, not all that glitters in collaborative learning is gold. The research literature on collaborative learning has amply demonstrated that instead of high quality interaction or transactive discussion, group members also often engage in interactive behaviors that are detrimental for their own and/or their group members' learning processes (Barron 2003; Janssen et al. 2007). Online discussions can be confusing to participants (Thompson and Coovert 2003), achieving shared understanding and common ground is often a problem (Beers et al. 2006; Kirschner et al. 2008), social loafing may occur (Latané et al. 1979), personal conflicts can arise (Hobman et al. 2002; O'Neill et al. 2013), and trying to reach consensus or making decisions can be time consuming during CSCL (Fjermestad 2004). In sum, during (online) collaboration students may experience collaborative processes that are extraneous to the essential processing of relevant information.

In CCLT, the interaction and communication processes that group members engage in during CSCL are referred to as transaction costs (Ciborra and Ohlson 1988; Kirschner et al. 2009a, 2018; Yamane 1996). When group members engage in transactive discussions and try to establish a transactive memory system, a considerable investment of cognitive 
resources is required: they need to engage in extensive coordination, social regulation, and communication (Janssen et al. 2010; Kirschner et al. 2009b; Salas et al. 2005). Although coordination and regulation is essential for managing the interdependencies between group members (Ellis et al. 1992; Erkens et al. 2005; Janssen et al. 2012; Malone and Crowston 1992), these strategies also require group members to invest considerable mental effort in those activities (Ciborra and Olson 1988; Janssen et al. 2010; Retnowati et al. 2018). As such, collaborating group members run the risk of experiencing their working memories while engaging in coordination, social regulation, and communication during CSCL, which will be deleterious to their learning.

Whether or not CSCL will be effective in a particular learning situation, therefore, depends on the balance that is struck between the distribution advantage on the one hand and the costs incurred by the transactive activities (Janssen et al. 2010; Kirschner et al. 2018) on the other hand. Kirschner et al. (2009a) hypothesized that when the distribution advantage that group members experience during collaborative learning is sufficiently large to compensate for the transaction costs that result from coordination and communication, collaborative learning will be more effective than individual learning. In contrast, when the transaction costs exceed the distribution advantage, individual learning will be more effective than collaborative learning. This latter situation may occur when, for example, group members are given a task that they are able to solve on their own. In such cases the distribution advantage experienced by group members is low, and it may not outweigh the transaction costs that they experience (Kirschner et al. 2009a).

This trade-off between the advantage of dividing information processing among group members on the one hand and the disadvantage of having to invest mental effort in transactive activities, has been called the collective working memory effect (Kirschner et al. 2011a, b; 2018). This effect was for example demonstrated in a study by Kirschner et al. (2011a) in the domain of biology. Secondary education students $(N=83)$ studied tasks on heredity individually or in 3-person groups. In addition, students encountered either high- or lowcomplexity tasks (i.e., tasks with more or fewer interacting novel information elements). The researchers expected to find an interaction effect between learning condition (individual vs. collaborative) and task complexity (low vs. high). Indeed, this interaction effect was confirmed: in the high complexity condition, groups outperformed individuals with respect to efficiency of learning (i.e., the ratio between invested mental effort and subsequent learning performance) while in the low complexity condition no such differences were found. In high complexity tasks, they concluded, the trade-off between the distribution advantage was sufficiently large to compensate for the transaction costs accrued during collaboration.

It should be noted, however, that not all communication, coordination, and regulation activities that occur during CSCL are detrimental for students' learning processes. Research on, for example, giving and receiving explanations during collaboration, has shown that giving elaborate explanations (e.g., explaining why a problem should be solved in a particular way) during group interaction correlates with higher achievement (Webb and Farrivar 1999; Webb and Mastergeorge 2003). Furthermore, work by Barron (2003) shows that constructively engaging with group members' ideas and proposals is correlated with better group performance. Finally, Janssen et al. (2012) showed that regulation activities, specifically activities that are aimed at regulating the group process (i.e., co-regulation and socially shared regulation of learning; Biasutti and Frate 2018; Järvelä et al. 2015), are positively correlated with better group performance. It would, therefore, be incorrect to dismiss all the transactive processes that occur in CSCL groups as detrimental to learning. On the other hand, although considerable effort has been invested to understand which 


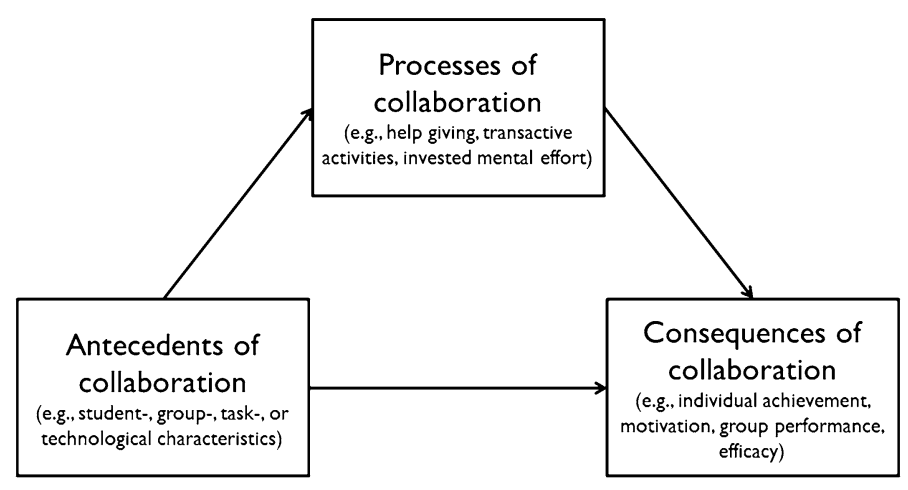

Fig. 1 Relationship between antecedents, processes, and consequences of collaboration

transactive processes predict individual achievement or group performance, a more comprehensive research agenda is needed to better understand why, how, and under which conditions transactive processes contribute to learning and performance. We will now outline how CCLT can be used to inform such a research agenda.

\section{Towards a research agenda}

In this section we describe the possibilities that we see for CSCL research inspired by CCLT. We do this by distinguishing between several characteristics that are important for CSCL. We will explain how CCLT can be used to formulate testable hypotheses and highlight relevant research that can be used to support those hypotheses. We will also pay attention to measurement of relevant variables; besides considering effectiveness and efficiency of learning, CSCL research should also focus on the processes of interaction. CCLT may also inspire how CSCL researchers operationalize these processes in order to measure them and, for example, relate them to the outcomes of online collaboration.

Research on CSCL can often be characterized as either effect-oriented research (e.g., Does a certain CSCL implementation affect student achievement? cf. Chen et al. 2018) or process-oriented research (e.g., How can students' interaction in a CSCL environment be characterized? cf. Stahl 2015). We argue that in order to gain a fundamental understanding of CSCL, it is necessary to study - simultaneously - the antecedents, processes, and consequences of the collaborative process during CSCL (see Fig. 1, cf. Janssen et al. 2010; Stodolsky 1984). The antecedents of collaboration refer to student-, group-, task-, or technological characteristics that affect the way students collaborate in CSCL environments (Le et al. 2018). The processes of collaboration refer to descriptions and qualities of the interactions between group members when they collaborate on a CSCL group task. They also include the (individual) learning activities group members engage in during the interaction. Finally, the consequences of collaboration refer to resulting effects of the antecedents and processes of collaboration (e.g., individual achievement, group performance, perceived efficacy). To fully understand the complexity of CSCL, it is necessary to conduct research that simultaneously studies the processes of collaboration, how these processes may be affected by the antecedents of collaboration, and how these interactions, in turn, affect the consequences of collaboration (Dillenbourg et al. 1996; Janssen et al. 2010). This 
Table 2 Antecedents relevant to CSCL and their elements

\begin{tabular}{ll}
\hline Characteristic & Possible elements \\
\hline $\begin{array}{l}\text { Student characteristics } \\
\text { Group characteristics }\end{array}$ & $\begin{array}{l}\text { prior knowledge, self-regulation skills, collaboration skills } \\
\text { group member familiarity, group experience, task experi- } \\
\text { ence, group size, group composition (heterogeneous vs. } \\
\text { homogeneous) }\end{array}$ \\
Task characteristics & $\begin{array}{l}\text { task complexity, type of interdependence } \\
\text { availability of collaboration scripts, scaffolds, awareness tools }\end{array}$ \\
\hline
\end{tabular}

way, it can be established how antecedents influence the processes of collaboration and its consequences and whether or how the processes of collaboration mediate the effect of antecedents on consequences of collaboration (see Fig. 1). Below, we describe how CCLT may inform hypotheses regarding the antecedents, processes and consequences of collaboration.

\section{Antecedents of collaboration}

Table 2 summarizes several antecedents of collaboration that are relevant to CSCL. These can be divided into student-, group-, task-, and technological characteristics (Kirschner et al. 2018; Van Meter and Stevens 2000). Each collaborative learning situation is influenced by these characteristics and their elements (see Table 2).

\section{Student characteristics}

In any classroom and thus in any CSCL scenario, there will be major differences between students. Some student characteristics, such as prior knowledge, self-regulation skills, and collaboration skills will affect the collaborative process and its outcomes. With respect to prior knowledge, two competing processes may be at play. First, for students with low prior knowledge of the learning material acquiring new knowledge during a complex collaborative problem solving task may be cognitively very demanding. It is likely that the extensive explorations of the problem space that are required in these situations will overload these learners' working memory, hampering their learning process (Kirschner et al. 2006; Sweller 1988). On the other hand, learners with low prior knowledge may obtain new knowledge and fill gaps in their knowledge from using knowledge and information provided by group members (Kirschner et al. 2018; Noorozi et al. 2013). Indeed, Congleton and Rajaram (2011) demonstrated that students can benefit from repeated exposure to information recalled by their partners. Furthermore, Retnowati et al. (2018) demonstrated that when students have incomplete information (e.g., as induced by a Jigsaw method), collaborative learning is superior to individual learning. Retnowati et al. (2018) also demonstrated that students with incomplete knowledge also experienced lower cognitive load. This can be interpreted as evidence for the existence of the borrowing and reorganization principle during collaboration (see Table 1). Unfortunately, most research investigating the role of prior knowledge has focused primarily on the relation between prior knowledge and consequences of collaboration (i.e., test performance). While individual learning processes have been considered (e.g., mental effort invested, cf. Retnowati et al. 2018), group processes or the process of collaboration itself (see Fig. 1) have not been investigated extensively (e.g., how does availability of prior knowledge affect students' contributions during 
the discussion?). In order to better understand the relationship between prior knowledge and learning, it is also necessary that researchers pay attention to for example the transactive activities low- and high prior knowledge group members engage in, to gain a more complete understanding of how low prior knowledge students obtain new information from their partners.

Other student characteristics that may be important to consider during CSCL are students' ability to self-regulate their learning process and their ability to collaborate (i.e., co-regulate and socially shared regulate the learning processes of others in the group; Järvelä et al. 2015). In both cases, it can be expected that when students possess these abilities this will lower the transaction costs experienced CSCL. Possessing adequate self-regulation and collaboration abilities will allow students to better communicate and coordinate their actions (Ellis et al. 1992; Janssen et al. 2012; Kirschner et al. 2018). In this research area, we see possibilities to combine the CSCL tradition to investigate collaboration and coordination processes (e.g., De Jong et al. 2005; Hadwin et al. 2010; Järvelä and Hadwin 2013) with measures of cognitive load, in order to examine the interplay between selfregulation and collaboration skills, the process of regulation and collaboration itself, the mental costs associated with these processes, and the resulting outcomes of CSCL.

\section{Group characteristics}

Besides considering student characteristics, it is also important to gain a better understanding of how group characteristics affect the processes and consequences of collaboration. Table 2 lists several group characteristics that are relevant to consider. In many cases, favorable group characteristics may positively impact groups' distribution advantage during CSCL; while at the same time lowering their transaction costs. For example with respect to group member familiarity, group members who are familiar with each other may experience fewer problems communicating and coordinating, thus lowering the extraneous load caused by these transactive activities (Janssen et al. 2009; 2010). Furthermore, this familiarity may also facilitate the borrowing and obtaining of new information from group members, thus strengthening the collective working memory effect. However, group member familiarity may not only have positive effects on the processes and consequences of collaboration. For example, research has demonstrated that in familiar groups, discussions can tend to more negative (e.g., interpersonal conflicts) compared to unfamiliar groups (Smolensky et al. 1990). This may indicate that in some situations familiar groups may experience additional non-effective transaction costs besides the benefit of the collective working memory effect. It is thus necessary that future research investigating the effects of this group characteristic, unearths exactly how and under which conditions familiarity affects the processes and outcomes of CSCL.

Prior group experience (e.g., the experience group members have with working with each other) and prior task experience (e.g., the experience group members have with collaborating on similar group tasks), may also help groups to more smoothly coordinate their actions, and thus lower the extraneous load caused by the collaboration process (Kirschner et al. 2018). Although prior CSCL research has considered group experience and familiarity (e.g., Adams et al. 2005; Janssen et al. 2009; Smolensky et al. 1990), these group characteristics have not been investigated from a CCLT perspective. Studies from a CCLT perspective could shed light on how these group characteristics affect the distribution advantage of groups and their transaction costs, and how these may mediate the effects of group member familiarity, group experience, task experience on collaborative outcomes. 
With respect to group size it seems that it is paramount for CSCL research to determine the tipping point between sufficiently large groups to establish a collective working memory effect (e.g., when groups are large, more collective information may be shared by group members) and smaller groups to keep the extraneous load caused by transactive activities at a minimum. It can, for example, be hypothesized that when group size increases, more transactive activities are necessary, some of which may hamper group members' learning process. To further complicate matters, task characteristics will probably moderate the effects of group size on collaborative processes and outcomes: more complex tasks will offer larger groups a more pronounced collective working memory effect, whereas this will probably not be the case for relatively simple tasks (Kirschner et al. 2009b). Another relevant task characteristic to consider may be the nature of the task: open vs. closed, divergent vs. convergent, ill- vs. well-structured (Cohen 1994; Kapur and Kinzer 2007). A large group may be advantageous for divergent tasks (i.e., more different types of expertise available), a smaller group for convergent tasks (i.e., less transaction costs required to pool information). We hope that CCLT will inspire CSCL researchers to investigate this complex interplay between group- and task characteristics.

Group composition may be one of the most difficult group characteristics to investigate in CSCL research. A first question that arises is: which elements are important to consider with respect to group composition? Previous CSCL research has investigated the role of group composition with respect to prior knowledge (e.g., Tomai et al. 2013; Wiedmann et al. 2012), but also for example with respect to gender (e.g., Postmes and Spears 2002; Van der Meijden and Veenman 2005). From a cognitive load perspective, group composition with respect to prior knowledge seems especially relevant. This was confirmed in the previously mentioned study by Zhang et al. (2016). In heterogeneous groups, students' learning achievements were greater than in homogeneous groups. However, Zhang et al. also demonstrated that prior knowledge as a student characteristics plays a role here: for students with little prior knowledge heterogeneous groups were most beneficial, whereas for students with high prior knowledge no difference was found between working in homogeneous or heterogeneous groups. Here we see another complication when investigating group composition: to investigate the effects of group composition effectively, it will be necessary to simultaneously take into account student characteristics as well (Cress 2008; Kenny et al. 2006).

\section{Task characteristics}

As we have previously discussed, task complexity is an important-if not the most important-task characteristic to consider during CSCL (Kirschner et al. 2009a; 2018). Effective collaboration may occur when a CSCL task is sufficiently complex to warrant the additional time and effort involved in collaborating with others. We do however think that research from a CCLT perspective can make further progress here by considering-besides individual processes such as experienced cognitive load-the collaborative process itself. Research by Kirschner et al. (2009b) and (2011a, b) has shed light on the relationship between task complexity, experienced cognitive load, and effectiveness of collaboration. It has however not elucidated which extraneous collaborative processes are disadvantageous for collaborative groups when working on relatively simple tasks. Nor has it pinpointed which collaborative processes contribute to the collective working memory effect experienced during complex tasks. We call for further research in this area that also pays 
attention to these collaborative and transactive processes when conducting research on task complexity during CSCL (Janssen et al. 2010).

Besides task complexity, interdependence is another factor to consider when investigating task characteristics. Interdependence exists when group members believe they can only reach their goals when the other group members also reach their goals (Johnson and Johnson 2009; Van Blankenstein et al. 2019). There are two common types of interdependence, namely outcome interdependence and means interdependence (Bertucci et al. 2016). The focus of outcome interdependence is that collaborative partners are mainly interdependent in achieving a common goal. This can be the successful accomplishment of a learning task or being given a group reward. Having a common goal or wanting to obtain a group reward is then the main reason for students to collaborate. In means interdependence, information is divided between group members (Johnson and Johnson 1999). Group members are then required to interact and communicate to obtain the necessary information from their group members to carry out the group task. Means interdependence is often used in Jigsaw procedures (Aronson and Bridgeman 1979). Means interdependence is known to result in higher quality interactions between team members, but may also increase the complexity of the learning task (Bertucci et al. 2012). Means interdependence causes information to be distributed very heterogeneously among group members. This may create difficulties for them to establish a transactive memory system (Hollingshead 2001), requiring more transactive activities (i.e., communication and coordination). As a result, group members may experience more extraneous load (Kirschner et al. 2018).

In a recent study, Nebel et al. (2017), examined how structuring means interdependence through the use of Jigsaw techniques affected learners' collaboration in the videogame Minecraft. As a result of the interdependence, Nebel et al. found that learning outcomes were increased. Interestingly, the study by Nebel et al., did not find an effect of interdependence on perceived cognitive load but showed an effect of interdependence on mental effort: students in the interdependence condition reported significantly higher invested mental effort compared to the control group. This study demonstrates that (1) interdependence has beneficial effects for students' learning, and (2) interdependence possibly requires increased transactive activities (as evidenced through the higher mental effort invested), although these activities need (wholly) not be detrimental for students' learning process.

\section{Technological characteristics}

Working on collaborative learning tasks requires adequate support and guidance (Kirschner et al. 2006). Technological characteristics to consider are the availability of collaboration scripts, the use of scaffolds, and the availability of awareness tools (Chen et al. 2018). What these approaches have in common is that they typically try to facilitate the process of problem solving (e.g., scaffolds) or the process of collaboration (e.g., scripts and awareness tools). For example, Bause et al. (2018) randomly assigned 219 students to groups of three and had them solve a hidden profile task. Hidden profile tasks (Stasser and Titus 1985) are tasks in which a group has to come to a decision (e.g., finding the best qualified candidate for an open position in a company) by aid of information items that are partially shared (i.e., given to all group members) and partially unshared within the group (i.e., only single group members have access to them). To support groups in their decision-making process, Bause et al. (2018) gave all triads the opportunity to work on a multi-touch table. They compared two conditions: In the control condition, each of the three group members had a private work space (represented on the multi-touch table) that contained all the given 
information pieces. In the experimental condition, groups additionally had a joint work space into which they were able to move information items from their private work spaces and cluster and merge them. Results showed that groups in the experimental condition showed greater discussion intensity, more indicators of mutual understanding, and better decision performance than groups in the control condition. Thus, in this case the scaffold offered through the multi-touch table may have helped students carry out their task and thus likely affected the cognitive load experienced by them.

Similarly, research on awareness tools (e.g., Janssen and Bodemer 2013) has shown that they can have an impact on the process of collaboration and on the consequences of collaboration (e.g., group performance, individual achievement). Janssen et al. (2011) demonstrated that when students used a social group awareness tool that visualized the amount of participation of each group member to the online discussion, the collaborative process was positively affected (e.g., more equal distribution of participation within the group). Furthermore, Lin et al. (2015) found that their social awareness tool not only positively affected the process of collaboration, but also students posttest performance. Although this indicates that awareness tools can affect the outcomes of CSCL in a positive manner, and that they can also affect the process of collaboration, research on awareness tools can make further progress by investigating these effects from a CCLT perspective. Such studies could for example investigate how such tools impact students' experienced cognitive load to better understand why and how they affect the processes and outcomes of collaboration. Furthermore, it is worthwhile to investigate how, for example, individual or group characteristics moderate the effects of awareness tools. It could be hypothesized that it is less necessary for familiar groups to have access to an awareness tool, as they might be able to better keep an overview of their group members' processes and activities due to their shared history. In these cases, such tools could even offer group members redundant or unnecessary information, causing additional extraneous load.

\section{Implications for instructional design of CSCL environments}

Based on our discussion of how CCLT may be used to inform research on how antecedents of collaboration affect the processes and outcomes of collaboration, we offer several guidelines for the instructional design of CSCL environments in Table 3. These guidelines are based on the principle that in order for effective collaboration to occur during CSCL, the collective working memory effect should be strengthened while at the same time keeping transaction costs to a minimum.

With respect to the guidelines presented in Table 3, we want to emphasize that further exploration and research is necessary to refine these guidelines for optimal application by instructional designers. While most of the research we have presented thus far is rooted in an experimental research tradition, we think that other research methodologies may also add to the knowledge base underpinning these instructional design guidelines. One such methodology is design-based research (DBR, cf. Anderson and Shattuck 2012; Barab and Squire 2004; McKenney and Reeves 2013). Several of the guidelines listed in Table 3, require careful consideration of an optimal arrangement for CSCL. For example, with respect group size, additional investigation is required to determine the optimal group size in a given CSCL situation. Careful application of DBR may yield invaluable additional knowledge with respect to the guidelines we offer. DBR has distinct features, such as being situated in a real educational context (as opposed to a laboratory setting), design and 
Table 3 Guidelines for instructional design of CSCL based on Collaborative Cognitive Load theory

\begin{tabular}{ll}
\hline Characteristic & Guideline \\
\hline Student characteristics & Students with low prior knowledge may obtain new knowledge from group \\
members with high prior knowledge \\
Securing a minimum of prior knowledge is necessary, as too little prior \\
knowledge will overload students' working memories \\
Paying attention to or scaffolding students' self-regulation and collaboration \\
skills, facilitates transactive activities \\
Increasing familiarity between group members facilitates transactive activi- \\
ties and strengthens collective working memory \\
Carefully using prior group and task experience allow for more smooth \\
coordination of activities \\
Optimal group size: Groups should not be too large to make sure the number \\
of transactive activities will not be too high. Groups should not be too \\
small in order to benefit from the collective working memory effect \\
Optimal heterogeneity with respect to prior knowledge: Heterogeneity allows \\
for the option to obtain new information from group members, but at the \\
same time increases the need for transactive activities \\
Complex tasks: Effective collaboration requires a task that is sufficiently \\
complex to justify the additional mental effort required by transactive \\
activities \\
Interdependence between group members will strengthen the quality of \\
interaction during collaboration and as a result the outcomes of collabora- \\
tion \\
Availability of collaboration scripts, scaffolds, and awareness tools can \\
facilitate transactive activities \\
Task characteristics
\end{tabular}

testing of an intervention in multiple iterations, and use of mixed methods (Anderson and Shattuck 2012).

\section{Processes of collaboration}

In the previous sections we outlined several antecedents of collaboration that are relevant to investigate from a CCLT perspective. As we have already argued, we think it would not be sufficient to merely investigate how these antecedents affect the consequences of collaboration (e.g., Does group composition affect effectiveness of CSCL? See Fig. 1). We think that CSCL research should also consider the processes of collaboration (e.g., Does group composition affect individual cognitive load or groups' transactive activities?).

Traditionally, cognitive load is measured-also in collaborative learning researchusing subjective measures. For example, in the studies by Kirschner et al. (2009b, 2011a, b) or Retnowati et al. (2018), the 9-point rating scale developed by Paas (1992) was used. However, the use of Paas' rating scale has its drawbacks in CSCL research. One drawback is that it gives a single measure of cognitive load, whereas the cognitive load experienced by group members during CSCL will probably vary over time. At some moments it may be quite low, in other moments it may reach a peak (Paa et al. 2003). To better understand how antecedents of collaboration affect cognitive load during the process of CSCL, it is necessary to develop and use new measures of cognitive load.

A promising way to shed further light on how cognitive load develops, is to use physiological data, such as electrodermal activity, skin temperature (Larmuseau et al. 2019; 
Pijeira-Diáz et al. 2018; Zheng 2018) or heart rate variability (Paas and Van Merriënboer 1994). When CSCL studies combine traditional cognitive load measures with physiological data, it would shed a more detailed light on how the antecedents of collaboration affect the process of collaboration on a moment-by-moment basis. This would allow a more detailed analysis of when group members experience periods of moderate cognitive load and when overload may occur. The study by Larmuseau et al. (2019) for example showed that peaks in students' electrodermal activity were related to specific complex phases in their problem-solving process. This shows that the measurement of electrodermal activity might shed more insight into how for example technological support can affect and alter these peaks.

CSCL research has a long tradition of examining the process of collaboration. Often, studies look at the kinds of contributions that individuals make to the discourse within the group. For example, Harney et al. (2017) investigated the effects of different kinds of prompts (task-level vs. task-plus-process-level prompts) on various indicators of individuals' argumentation quality that were assessed through content analysis of verbal protocols. However, examining such textual features of collaboration may also shed light on the cognitive load students experience during collaboration. Khawaja et al. for example (2009) were able to demonstrate that linguistic, and grammatical features of collaboration affected cognitive load. Khawaja et al. noted significantly longer speech pauses and significantly less use of singular pronouns (e.g., "I", "you"), when cognitive load was high. Other elements of collaborative speech, have also been shown to be related to cognitive load. For example when there are more pauses during speech, or when there are more peaks in the pitch of speech, cognitive load is higher (Yin and Chen 2007). Such studies provide insight into which features of collaborative speech are related to cognitive load and cognitive overload, and show that aspects of the collaborative process can be used as non-intrusive measures cognitive load.

\section{A CCLT research agenda may require new methodologies}

After considering how CCLT may inspire new avenues of inquiry to study the antecedents, processes, and consequences of collaboration, we finally turn our attention to methodological issues. While we think applying CCLT to CSCL research may inspire researchers to pursue new research questions, we also think this should go hand in hand with methodological developments as well. We see four particularly pressing methodological developments that are necessary to reap the full benefit of using CCLT for new CSCL research. These are: measurement of cognitive load, taking into account multiple levels of analysis, taking into account temporality, expanding the breadth of research methodologies.

As we have explained above, using subjective rating scales to measure cognitive load have their merits for CSCL research from a CCLT perspective. We, however, think that additional progress can be made in measuring cognitive load during online and face-toface collaboration. We think it is of particular importance that new approaches to measure cognitive load allow for the scrutiny of the development of cognitive load over time (Paas et al. 2003). Physiological data allow researchers to study learners' physical reactions on a moment-by-moment basis, and may help them to pinpoint when peaks in cognitive load occur and how these are for example related to group- or technological characteristics (Janssen et al. 2010). We acknowledge that further research is necessary to determine which physiological measures are adequately suited to measure cognitive load; as this is 
a necessary first step to supplement traditional subjective measure of cognitive load with new measures (Larmuseau et al. 2019).

A second necessary methodological development is that research from a CCLT perspective takes multiple levels of analysis into account. Many variables that are valuable to study from a CCLT perspective operate at multiple levels and may influence each other reciprocally. Consider for example prior knowledge. This variable can be considered a student characteristic and it is indeed worthwhile to study this variable on the level of the individual. Such research then examines how a student's prior knowledge shapes how she or he behaves during online collaboration, and how this in turn affects individual achievement. However, prior knowledge also operates on the level of the group and can thus also be considered a relevant group characteristic: in some groups more prior knowledge is available than in others. We think it is paramount that CSCL research from a CCLT perspective addresses the effects of such variables on these multiple levels. In other words, future CSCL studies that investigate the effects of prior knowledge on the process of collaboration and its outcomes, should not neglect the group aspect of prior knowledge. This means that such studies should investigate both how individual prior knowledge and group prior knowledge affect processes and outcomes of collaboration, and also how individual and group prior knowledge may interact. We point the interested reader toward the Group Actor-Partner Interdependence Model developed by Kenny et al. (e.g., Garcia et al. 2015; Kenny and Garcia 2012). Using this model, researchers may, for example, disentangle how individual prior knowledge, prior knowledge of the students' collaboration partners, and the interaction between individual and partners' prior knowledge affects the process of collaboration and its outcomes. We think that the use of more advanced statistical techniques that help researchers take into multiple levels of analysis, will further advance our understanding of CSCL.

The goal of CCLT is to understand the human endeavor of collaboration. This requires the combined study of the antecedents, processes, and outcomes of collaboration. Doing justice to such a stance, would require researchers to attempt to study collaborating groups as dynamic systems (cf. Granic and Patterson 2006). This would mean that research not only pays attention to behavior and cognition of the individual within the group, but would also require paying attention to the social and cultural context within which the individual operates while interacting with this context and with group members (Greeno et al. 1988). As we have argued before (see Janssen et al. 2010), we think that this means that research from a CCLT perspective also pays attention to the detailed study of the process of collaboration itself and how this process unfolds over time. A combined focus on the antecedents of collaboration (including the social and cultural context of the individual and the group) and the process of collaboration will ultimately enhance of the outcomes of collaboration.

Next, we wish to stress - as other researchers have done (e.g., Popov et al. 2017; Reimann 2009) - that it is important to take temporal aspects into account during CSCL research. We agree with Reimann (2009) that the process of collaboration unfolds over time, and that studying events (alongside variables) and the order of events gives a more complete of how the process of collaboration develops. Recently developed statistical techniques, such as Dynamic Bayesian Networks (Russel and Norvig 2016), and the availability of packages to employ these techniques in common software like R, allow researchers to for example study how transactive activities develop and how they contribute to the development of students' cognitive load.

Finally, we think that it is important that CSCL research that is conducted from a CCLT perspective expands its methodological breadth. As we have noted earlier, most research on CSCL from this perspective is rooted firmly in an experimental tradition. Surely, this 
way of doing research will advance our knowledge of how the antecedents of collaboration affect the process of collaboration and its outcomes. However, other research methodologies may also be used to gain a further understanding of the interrelationships outlined in Fig. 1 or the instructional guidelines for CSCL offered in Table 3. By expanding the breadth of methodologies used, to incorporate for example design-based research, we may gain additional understanding of CSCL design. This will be invaluable to instructional designers of CSCL scenarios.

\section{Conclusion}

Collaborative Cognitive Load Theory (CCLT) stresses that the advantages (collective working memory effect) and disadvantages (transaction costs) should be taken into account when making decisions about the design of collaborative learning environments. When these advantages and disadvantages are not sufficiently considered, the outcomes of CSCL may be less positive than expected. In this contribution, we wanted to show how CCLT may be used to further guide CSCL research. CSCL research guided by CCLT could enhance our understanding of the advantages and disadvantages of online collaboration. This could ultimately yield instructional design principles that can be used by educators to make informed decisions about the use of CSCL that increase the chances of the desired learning goals to be attained.

\section{Compliance with ethical standards}

Conflict of interest The authors declare that they have no conflict of interest.

Informed consent No data was collected for this manuscript, thus no informed consent was obtained.

Research involving human and animal rights This article does not contain any studies with human participants performed by any of the authors.

Open Access This article is licensed under a Creative Commons Attribution 4.0 International License, which permits use, sharing, adaptation, distribution and reproduction in any medium or format, as long as you give appropriate credit to the original author(s) and the source, provide a link to the Creative Commons licence, and indicate if changes were made. The images or other third party material in this article are included in the article's Creative Commons licence, unless indicated otherwise in a credit line to the material. If material is not included in the article's Creative Commons licence and your intended use is not permitted by statutory regulation or exceeds the permitted use, you will need to obtain permission directly from the copyright holder. To view a copy of this licence, visit http://creativecommons.org/licenses/by/4.0/.

\section{References}

Adams, S. J., Roch, S. G., \& Ayman, R. (2005). Communication medium and member familiarity: The effects on decision time, accuracy, and satisfaction. Small Group Research, 36, 321-353. https://doi. org/10.1177/1046496405275232.

Anderson, T., \& Shattuck, J. (2012). Design-based research: A decade of progress in education research? Educational Researcher, 41, 16-25. https://doi.org/10.3102/0013189X11428813.

Aronson, E., \& Bridgeman, D. (1979). Jigsaw groups and the desegregated classroom: In pursuit of common goals. Personality and Social Psychology Bulletin, 5, 438-446. https://doi.org/10.1177/01461 6727900500405 . 
Asterhan, C. S. C., \& Schwarz, B. B. (2016). Argumentation for learning: Well-trodden paths and unexplored territories. Educational Psychologist, 51(2), 164-187. https://doi.org/10.1080/00461 520.2016 .1155458$.

Atkinson, R. K., Derry, S. J., Renk1, A., \& Wortham, D. (2000). Learning from examples: Instructional principles from the worked examples research. Review of Educational Research, 70(2), 181-214. https:// doi.org/10.3102/00346543070002181.

Barab, S., \& Squire, B. (2004). Design-based research: Putting a stake in the ground. Journal of the Learning Sciences, 13, 1-14. https://doi.org/10.1207/s15327809j1s1301_1.

Barron, B. (2003). When smart groups fail. Journal of the Learning Sciences, 12, 307-359. https://doi. org/10.1207/S15327809JLS1203_1.

Bause, I. M., Brich, I. R., Wesslein, A.-K., \& Hesse, F. W. (2018). Using technological functions on a multi-touch table and their affordances to counteract biases and foster collaborative problem solving. International Journal of Computer-Supported Collaborative Learning, 13, 7-33. https://doi. org/10.1007/s11412-018-9271-4.

Beers, P. J., Boshuizen, H. P. A., Kirschner, P. A., \& Gijselaers, W. H. (2006). Common ground, complex problems and decision making. Group Decision and Negotiation, 15, 529-556. https://doi. org/10.1007/s10726-006-9030-1.

Bertucci, A., Johnson, D. W., Johnson, R. T., \& Conte, S. (2012). Influence of group processing on achievement and perception of social and academic support in elementary inexperienced cooperative learning groups. The Journal of Educational Research, 105, 329-335. https://doi. org/10.1080/00220671.2011.627396.

Bertucci, A., Johnson, D. W., Johnson, R. T., \& Conte, S. (2016). Effect of task and goal interdependence on achievement, cooperation, and support among elementary school students. International Journal of Educational Research, 79, 97-105. https://doi.org/10.1016/j.ijer.2016.06.011.

Biasutti, M., \& Frate, S. (2018). Group metacognition in online collaborative learning: Validity and reliability of the group metacognition scale (GMS). Educational Technology Research and Development, 66, 1321-1338. https://doi.org/10.1007/s11423-018-9583-0.

Buchs, C., \& Butera, F. (2009). Is a partner's competence threatening during dyadic cooperative work? It depends on resource interdependence. European Journal of Psychology of Education, 24, 145154. https://doi.org/10.1007/BF03173007.

Buchs, C., Butera, F., \& Mugny, G. (2004). Resource interdependence, student interactions and performance in cooperative learning. Educational Psychology, 24, 291-314. https://doi. org/10.1080/0144341042000211661.

Capar, G., \& Tarim, K. (2015). Efficacy of the cooperative learning method on mathematics achievement and attitude: A meta-analysis research. Educational Sciences: Theory \& Practice, 15, 553-559. https://doi.org/10.12738/estp.2015.2.2098.

Chen, O., Kalyuga, S., \& Sweller, J. (2016a). The expertise reversal effect is a variant of the more general element interactivity effect. Educational Psychology Review, 29, 1-13. https://doi. org/10.1007/s10648-016-9359-1.

Chen, J., Wang, M., Kirschner, P. A., \& Tsai, C.-C. (2018). The role of collaboration, computer use, learning environments, and supporting strategies in CSCL: A meta-analysis. Review of Educational Research, 88, 799-843. https://doi.org/10.3102/0034654318791584.

Chen, O., Kalyuga, S., \& Sweller, J. (2016b). The expertise reversal effect is a variant of the more general element interactivity effect. Educational Psychology Review, https://doi.org/10.1007/s1064 8-016-9359-1.

Ciborra, C., \& Olson, M. H. (1988). Encountering electronic work groups: A transaction costs perspective. In: Proceedings of the 1988 ACM conference on computer-supported cooperative work. Portland, OR: ACM. https://doi.org/10.1145/62266.62274.

Cohen, E. G. (1994). Restructuring the classroom: Conditions for productive small groups. Review of Educational Research, 64, 1-35.

Congleton, A. R., \& Rajaram, S. (2011). The influence of learning methods on collaboration: Prior repeated retrieval enhances retrieval organization, abolished collaborative inhibition, and promotes post-collaborative memory. Journal of Experimental Psychology: General, 140, 535-551. https://doi.org/10.1037/a0024308.

Cress, U. (2008). The need for considering multilevel analysis in CSCL research: An appeal for the use of more advanced statistical methods. International Journal of Computer-Supported Collaborative Learning, 3, 69-84. https://doi.org/10.1007/s11412-007-9032-2.

De Dreu, C. K. W., Nijstad, B. A., \& Van Knippenberg, D. (2008). Motivated information processing in group judgment and decision making. Personality and Social Psychology Review, 12, 22-49. https ://doi.org/10.1177/1088868307304092 
De Jong, F., Kollöffel, B., Van der Meijden, H., Staarman, J. K., \& Janssen, J. (2005). Regulative processes in individual, 3D and computer supported cooperative learning contexts. Computers in Human Behavior, 21, 645-670. https://doi.org/10.1016/j.chb.2004.10.023.

Dillenbourg, P., Baker, M., Blaye, A., \& O’Malley, C. (1996). The evolution of research on collaborative learning. In E. Spada \& P. Reiman (Eds.), Learning in humans and machine: Towards an interdisciplinary learning science (pp. 189-211). Oxford: Elsevier.

Ellis, C. A., Gibbs, S. J., \& Rein, G. (1992). Groupware: Some issues and experiences. In D. Marca \& G. Bock (Eds.), Groupware: Software for computer-supported cooperative work (pp. 23-43). Los Alamitos, CA: IEEE Computer Society Press.

Erkens, G., Jaspers, J., Prangsma, M., \& Kanselaar, G. (2005). Coordination processes in computer supported collaborative writing. Computers in Human Behavior, 21, 463-486. https://doi. org/10.1016/j.chb.2004.10.038.

Fjermestad, J. (2004). An analysis of communication mode in group support systems research. Decision Support Systems, 37, 239-263. https://doi.org/10.1016/S0167-9236(03)00021-6.

Garcia, R. L., Meagher, B. R., \& Kenny, D. A. (2015). Analyzing the effects of group members' characteristics: A guide to the group actor-partner interdependence model. Group Processes \& Intergroup Relations, 18, 315-328. https://doi.org/10.1177/1368430214556370.

Geary, D. (2012). Evolutionary educational psychology. In K. Harris, S. Graham, \& T. Urdan (Eds.), APA Educational psychology handbook (Vol. 1, pp. 597-621). Washington, DC: American Psychological Association.

Gijlers, H., \& De Jong, T. (2013). Using concept maps to facilitate collaborative simulation-based inquiry learning. Journal of the Learning Sciences, 22, 340-374. https://doi.org/10.1080/10508 406.2012.748664.

Granic, I., \& Patterson, G. R. (2006). Towards a comprehensive model of antisocial development: A dynamic systems approach. Psychological Review, 113, 101-131. https://doi. org/10.1037/0033-295X.113.1.101.

Greeno, J. G., \& the Middle School Mathematics Through Applications Project Group. (1988). The situativity of knowing, learning, and research. American Psychologist, 53(1), 5-26.

Hadwin, A. F., Bakhtiar, A., \& Miller, M. (2018). Challenges in online collaboration: Effects of scripting shared task perceptions. International Journal of Computer-Supported Collaborative Learning, 13, 301-329. https://doi.org/10.1007/s11412-018-9279-9.

Hadwin, A. F., Oshige, M., Gress, C. L. Z., \& Winne, P. H. (2010). Innovative ways for using gStudy to orchestrate and research social aspects of self-regulated learning. Computers in Human Behavior, 26, 794-805. https://doi.org/10.1016/j.chb.2007.06.007.

Harney, O. M., Hogan, M. J., \& Quinn, S. (2017). Investigating the effects of peer to peer prompts on collaborative argumentation, consensus and perceived efficacy in collaborative learning. International Journal of Computer-Supported Collaborative Learning, 12, 307-336. https://doi. org/10.1007/s11412-017-9263-9.

Hobman, E. V., Bordia, P., Irmer, B., \& Chang, A. (2002). The expression of conflict in computer-mediated and face-to-face groups. Small Group Research, 33, 439-465. https://doi.org/10.1177/10464 9640203300403.

Hollingshead, A. B. (2001). Cognitive interdependence and convergent expectations in transactive memory. Journal of Personality and Social Psychology, 81, 1080-1089. https://doi. org/10.1037/0022-3514.81.6.1080.

Janssen, J., \& Bodemer, D. (2013). Coordinated computer-supported collaborative learning: Awareness and awareness tools. Educational Psychologist, 48, 40-55. https://doi.org/10.1080/00461 520.2012 .749153 .

Janssen, J., Erkens, G., Kanselaar, G., \& Jaspers, J. (2007). Visualization of participation: Does it contribute to successful computer-supported collaborative learning? Computers \& Education, 49, 1037-1065. https://doi.org/10.1016/j.compedu.2006.01.004.

Janssen, J., Erkens, G., Kirschner, P. A., \& Kanselaar, G. (2009). Influence of group member familiarity on online collaborative learning. Computers in Human Behavior, 25, 161-170. https://doi. org/10.1016/j.chb.2008.08.010.

Janssen, J., Kirschner, F., Erkens, G., Kirschner, P. A., \& Paas, F. (2010). Making the black box of collaborative learning transparen: Combining process-oriented and cognitive load approaches. Educational Psychology Review, 22, 139-154. https://doi.org/10.1007/s10648-010-9131-x.

Janssen, J., Erkens, G., Kirschner, P. A., \& Kanselaar, G. (2012). Task-related and social regulation during online collaborative learning. Metacognition and Learning, 7, 25-43. https://doi.org/10.1007/ s11409-010-9061-5. 
Järvelä, S. M., \& Hadwin, A. (2013). New frontiers: Regulating learning in CSCL. Educational Psychologist, 48, 25-39. https://doi.org/10.1080/00461520.2012.74800.

Järvelä, S., Kirschner, P. A., Panadero, E., Malmberg, J., Phielix, C., Jaspers, J., et al. (2015). Enhancing socially shared regulation in collaborative learning groups: Designing for CSCL regulation tools. Educational Technology Research and Development, 63, 125-142. https://doi.org/10.1007/s1142 3-014-9358-1...

Johnson, D. W., \& Johnson, R. T. (1999). Learning together and alone: Cooperative, competitive, and individualistic learning (5th ed.). Boston: Allyn and Bacon.

Johnson, D. W., \& Johnson, R. T. (2009). An educational psychology success story: Social interdependence theory and cooperative learning. Educational Researcher, 38, 365-379. https://doi. org/10.3102/0013189X09339057.

Johnson, D. W., Johnson, R. T., \& Stanne, M. B. (1989). Impact of goal and resource interdependence on problem-solving success. The Journal of Social Psychology, 129(5), 621-629. https://doi. org/10.1080/00224545.1989.9713780.

Kalyuga, S., Chandler, P., \& Sweller, J. (1998). Levels of expertise and instructional design. Human Factors: The Journal of the Human Factors and Ergonomics Society, 40(1), 1-17. https://doi. org/10.1518/001872098779480587.

Kapur, M., \& Kinzer, C. K. (2007). Examining the effect of problem type in a synchronous computersupported collaborative learning (CSCL) environment. Educational Technology Research and Development, 55, 439-459. https://doi.org/10.1007/s11423-007-9045-6.

Kenny, D. A., \& Garcia, R. L. (2012). Using the actor-partner interdependence model to study the effects of group composition. Small Group Research, 43, 468-496. https://doi.org/10.1177/10464 96412441626.

Kenny, D. A., Kashy, D. A., \& Cook, W. L. (2006). Dyadic data analysis. New York: The Guilford Press.

Khawaja, M. A., Chen, F., \& Marcus, N. (2009). Analysis of collaborative speech for grammatical cues of cognitive load. Paper presented at the Third international cognitive load theory conference, Heerlen, The Netherlands.

Kirschner, F., Paas, F., \& Kirschner, P. A. (2009a). A cognitive-load approach to collaborative learning: United brains for complex tasks. Educational Psychology Review, 21, 31-42. https://doi. org/10.1007/s10648-008-9095-2.

Kirschner, F., Paas, F., \& Kirschner, P. A. (2009b). Individual and group-based learning from complex cognitive tasks: Effects on retention and transfer efficiency. Computers in Human Behavior, 25, 306-314. https://doi.org/10.1016/j.chb.2008.12.008.

Kirschner, F., Paas, F., \& Kirschner, P. A. (2011a). Task complexity as a driver for collaborative learning efficiency: The collective working-memory effect. Applied Cognitive Psychology, 25, 615-624. https://doi.org/10.1002/acp.1730.

Kirschner, F., Paas, F., Kirschner, P. A., \& Janssen, J. (2011b). Differential effects of problem-solving demands on individual and collaborative learning outcomes. Learning and Instruction, 21, 587599. https://doi.org/10.1016/j.learninstruc.2011.01.001.

Kirschner, P. A., Beers, P. J., Boshuizen, H. P. A., \& Gijselaers, W. H. (2008). Coercing shared knowledge in collaborative learning environments. Computers in Human Behavior, 24, 403-420. https:// doi.org/10.1016/j.chb.2007.01.028.

Kirschner, P. A., \& Erkens, G. (2013). Toward a framework for CSCL research. Educational Psychologist, 48, 1-8. https://doi.org/10.1080/00461520.2012.750227.

Kirschner, P. A., Sweller, J., \& Clark, R. E. (2006). Why minimal guidance during instruction does not work: An analysis of the failure of constructivist, discovery, problem-based, experiential, and inquiry-based teaching. Educational Psychologist, 41, 75-86. https://doi.org/10.1207/s15326985e p4102_1.

Kirschner, P. A., Sweller, J., Kirschner, F., \& Zambrano, R. J. (2018). From cognitive load theory to collaborative cognitive load theory. International Journal of Computer-Supported Collaborative Learning, 13, 213-233. https://doi.org/10.1007/s11412-018-0277-y.

Kolloffel, B., Eysink, T. H. S., \& De Jong, T. (2011). Comparing the effects of representational tools in collaborative and individual inquiry learning. International Journal of Computer-Supported Collaborative Learning, 6, 223-251. https://doi.org/10.1007/s11412-011-9110-3.

Kreijns, K., Kirschner, P. A., Jochems, W., \& Van Buuren, H. (2007). Measuring perceived sociability of computer-supported collaborative learning environments. Computers \& Education, 49, 176-192. https://doi.org/10.1016/j.compedu.2005.05.004.

Kyndt, E., Raes, E., Lismont, B., Timmers, F., Cascallar, E., \& Dochy, F. (2013). A meta-analysis of the effects of face-to-face cooperative learning. Do recent studies falsify or verify earlier findings? Educational Research Review, 10, 133-149. https://doi.org/10.1016/j.edurev.2013.02.002. 
Larmuseau, C., Vanneste, P., Cornelis, J., Desmet, P., \& Depaepe, F. (2019). Combining physiological data and subjective measurements to investigate cognitive load during complex learning. Frontline Learning Research, 7, 57-74. https://doi.org/10.14786/flr.v7i2.403.

Latané, B., Williams, K., \& Harkins, S. (1979). Many hands make light work: The causes and consequences of social loafing. Journal of Personality and Social Psychology, 37, 822-883. https://doi. org/10.1037/0022-3514.37.6.822.

Le, H., Janssen, J., \& Wubbels, T. (2018). Collaborative learning practices: Teacher and student perceived obstacles to effective student collaboration. Cambridge Journal of Education, 48, 103-122. https://doi.org/10.1080/0305764X.2016.12593896.

Lin, J.-W., Mai, L.-J., \& Lai, Y.-C. (2015). Peer interaction and social network analysis of online communities with the support of awareness of different contexts. International Journal of Computer-Supported Collaborative Learning, 10(2), 139-159.

Lou, Y., Abrami, P., Spence, J., Poulsen, C., Chambers, B., \& d'Apollonia, S. (1996). Within-class grouping: A meta-analysis. Review of Educational Research, 66, 423-458. https://doi.org/10.3102/00346 543066004423.

Malone, T. W., \& Crowston, K. (1992). What is coordination theory and how can it help design cooperative work systems? In D. Marca \& G. Bock (Eds.), Groupware: Software for computer-supported cooperative work (pp. 100-113). Los Alamitos, CA: IEEE Computer Society Press.

McKenney, S., \& Reeves, C. (2013). Systematic review of design-based research progress: Is a little knowledge a dangerous thing? Educational Researcher, 42, 97-100. https://doi.org/10.3102/0013189X12 463781 .

Nebel, S., Schneider, S., Beege, M., Kolda, F., Mackiewicz, V., \& Rey, G. D. (2017). You cannot do this alone! Increasing task interdependence in cooperative educational videogames to encourage collaboration. Educational Technology Research and Development, 65, 993-1014. https://doi.org/10.1007/ s11423-017-9511-8.

Noroozi, O., Teasley, S. D., Biemans, H. J. A., Weinberger, A., \& Mulder, M. (2013). Facilitating learning in multidisciplinary groups with transactive CSCL scripts. International Journal of Computer-Supported Collaborative Learning, 8, 189-223. https://doi.org/10.1007/s11412-012-9162-z.

O'Neill, T. A., Allen, N. J., \& Hastings, S. E. (2013). Examining the "pros" and "cons" of team conflict: A team-level meta-analysis of task, relationship, and process conflict. Human Performance, 26, 236260. https://doi.org/10.1080/08959285.2013.795573.

Paas, F., Tuovinen, J. E., Tabbers, H., \& Van Gerven, P. W. M. (2003). Cognitive load measurement as a means to advance cognitive load theory. Educational Psychologist, 38, 63-71. https://doi. org/10.1207/S15326985EP3801_8.

Paas, F., \& Van Merriënboer, J. J. G. (1994). Instructional control of cognitive load in the training of complex cognitive tasks. Educational Psychology Review, 6, 351-371.

Paas, F. G. (1992). Training strategies for attaining transfer of problem-solving skill in statistics: A cognitive load approach. Journal of Educational Psychology, 84, 429-434. https://doi. org/10.1037/0022-0663.84.4.429.

Pijeira-Diáz, H. J., Drachsler, H., Kirschner, P. A., \& Järvelä, S. (2018). Profiling sympathetic arousal in a physics course: How active are students? Journal of Computer Assisted Learning, 34, 397-408. https ://doi.org/10.1111/jcal.12271.

Popov, V., Van Leeuwen, A., \& Buijs, S. C. A. (2017). Are you with me or not? Temporal synchronicity and transactivity during CSCL. Journal of Computer Assisted Learning, 33, 424-442. https://doi. org/10.1111/jcal.12185.

Postmes, T., \& Spears, R. (2002). Behavior online: Does anonymous computer communication reduce gender inequality? Personality and Social Psychology Bulletin, 28, 1074-1083. https://doi. org/10.1177/01461672022811006.

Reimann, P. (2009). Time is precious: Variable- and event-centred approaches to process analysis in CSCL research. International Journal of Computer-supported Collaborative Learning, 4, 239-257. https:// doi.org/10.1007/s11412-009-9070-z.

Retnowati, E., Ayres, P., \& Sweller, J. (2017). Can collaborative learning improve the effectiveness of worked examples in learning mathematics? Journal of Educational Psychology, 109, 666-679. https ://doi.org/10.1037/edu0000167.

Retnowati, E., Ayres, P., \& Sweller, J. (2018). Collaborative learning effects when students have complete or incomplete knowledge. Applied Cognitive Psychology, 32, 681-692. https://doi.org/10.1002/ acp.3444.

Roseth, C. J., Johnson, D. W., \& Johnson, R. T. (2008). Promoting early adolescents' achievement and peer relationships: The effects of cooperative, competitive, and individualistic goal structures. Psychological Bulletin, 134, 223-246. https://doi.org/10.1037/0033-2909.134.2.223. 
Russell, S., \& Norvig, P. (2016). Artificial intelligence: A modern approach (3rd ed.). Harlow: Pearson Education Limited.

Salas, E., Sims, D. E., \& Burke, C. S. (2005). Is there a "big five" in teamwork? Small Group Research, 36, 555-599. https://doi.org/10.1177/1046496405277134.

Schnaubert, L., \& Bodemer, D. (2019). Providing different types of group awareness information to guide collaborative learning. International Journal of Computer-Supported Collaborative Learning, 14, 7-51. https://doi.org/10.1007/s11412-018-9293-y.

Silverman, B. G. (1995). Computer supported collaborative learning (CSCL). Computers \& Education, 25, 81-91. https://doi.org/10.1016/0360-1315(95)00059-3.

Smolensky, M. A., Carmody, M. A., \& Halcomb, C. G. (1990). The influence of task type, group structure and extraversion on uninhibited speech in computer-mediated communication. Computers in Human Behavior, 6, 261-272. https://doi.org/10.1016/0747-5632(90)90022-9.

Stahl, G. (2015). A decade of CSCL research. International Journal of Computer-Supported Collaborative Learning, 10, 337-344. https://doi.org/10.1007/s11412-015-9222-2.

Stasser, G., \& Titus, W. (1985). Pooling of unshared information in group decision making: Biased information sampling during discussion. Journal of Personality and Social Psychology, 48, 14671478. https://doi.org/10.1037/0022-3514.48.6.1467.

Stodolsky, S. S. (1984). Frameworks for studying instructional processes in peer work-groups. In P. L. Peterson, L. C. Wilkinson, \& M. Hallinan (Eds.), The social context of instruction: Group organization and group processes (pp. 107-124). Orlando, FL: Academic Press Inc.

Strijbos, J.-W., Martens, R. L., Jochems, W. M., \& Broers, N. J. (2007). The effect of functional roles on perceived group efficiency during computer-supported collaborative learning: A matter of triangulation. Computers in Human Behavior, 23, 353-380. https://doi.org/10.1016/j.chb.2004.10.016.

Sweller, J. (1988). Cognitive load during problem solving: Effects on learning. Cognitive Science, 12, 257-285. https://doi.org/10.1207/s15516709cog1202_4.

Sweller, J. (2010). Element interactivity and intrinsic, extraneous and germane cognitive load. Educational Psychology Review, 22, 123-138. https://doi.org/10.1007/s10648-010-9128-5.

Sweller, J., Kirschner, P. A., \& Clark, R. E. (2007). Why minimally guided teaching techniques do not work: A reply to commentaries. Educational Psychologist, 42, 115-121. https://doi. org/10.1080/00461520701263426.

Sweller, J., \& Sweller, S. (2006). Natural information processing systems. Evolutionary Psychology, 4, 434-458. https://doi.org/10.1177/147470490600400135.

Teasley, S. D. (1997). Talking about reasoning: How important is the peer in peer collaboration? In L. B. Resnick, R. Säljö, C. Pontecorvo, \& B. Burge (Eds.), Discourse, tools and reasoning: Essays on situated cognition (pp. 361-384). Berlin: Springer.

Teasley, S. D., \& Roschelle, J. (1993). Constructing a joint problem space: The computer as a tool for sharing knowledge. In S. P. Lajoie (Ed.), Computers as cognitive tools: Technology in education (pp. 229-258). Hillsdale, NJ: Lawrence Erlbaum Associates Inc.

Thompson, L. F., \& Coovert, M. D. (2003). Teamwork online: The effects of computer conferencing on perceived confusion, satisfaction and postdiscussion accuracy. Group Dynamics, 7, 135-151. https ://doi.org/10.1037/1089-2699.7.2.135.

Tindale, R. S., \& Kameda, T. (2000). Social sharedness as a unifying theme for information processing in groups. Group Processes \& Intergroup Relations, 3, 123-140. https://doi.org/10.1177/13684 30200003002002 .

Tomai, M., Mebane, M. E., Rosa, V., Ingravalle, V., \& Benedetti, M. (2013). Do virtual groups experience less conflict than traditional teams? AWER Procedia Information Technology \& Computer Science, 4, 926-938.

Van Meter, P., \& Stevens, R. J. (2000). The role of theory in the study of peer collaboration. Journal of Experimental Education, 69, 113-127. https://doi.org/10.1080/00220970009600652.

Van Amelsvoort, M., Andriessen, J., \& Kanselaar, G. (2007). Representational tools in computersupported collaborative argumentation-based learning: How dyads work with constructed and inspected argumentative diagrams. Journal of the Learning Sciences, 16, 485-521. https://doi. org/10.1080/10508400701524785.

Van Blankenstein, F. M., Saab, N., Van der Rijst, R. M., Danel, M. S., Bakker-van den Berg, A. S., \& Van den Broek, P. W. (2019). How do self-efficacy beliefs for academic writing and collaboration and intrinsic motivation for academic writing and research develop during an undergraduate research project? Educational Studies, 45, 1-17. https://doi.org/10.1080/03055698.2018.1446326.

Van der Meijden, H., \& Veenman, S. (2005). Face-to-face versus computer-mediated communication in a primary school setting. Computers in Human Behavior, 21, 831-859. 
Vogel, F., Wecker, C., Kollar, I., \& Fischer, F. (2017). Socio-cognitive scaffolding with computer-supported collaboration scripts: A meta-analysis. Educational Psychology Review, 29, 477-511. https ://doi.org/10.1007/s10648-016-9361-7.

Warfa, A.-R. M. (2016). Using cooperative learning to teach chemistry: A meta-analytic review. Chemical Education Research, 93, 248-255. https://doi.org/10.1021/acs.jchemed.5b00608.

Webb, N. M., \& Farivar, S. (1999). Developing productive group interaction in middle school mathematics. In A. O’Donnell \& A. King (Eds.), Cognitive perspectives on peer learning (pp. 117-149). Mahwah, NJ: Lawrence Erlbaum Associates.

Webb, N. M., \& Mastergeorge, A. (2003). Promoting effective helping behavior in peer-directed groups. International Journal of Educational Research, 39, 73-97. https://doi.org/10.1016/S0883 -0355(03)00074-0.

Wegner, D. M. (1987). Transactive memory: A contemporary analysis of the group mind. In B. Mullen \& G. R. Goethals (Eds.), Theories of group behavior (pp. 185-208). New York: Springer.

Wegner, D. M. (1995). A computer network model of human transactive memory. Social Cognition, 13, 319-339.

Wiedmann, M., Leach, R. C., Rummel, N., \& Wiley, J. (2012). Does group composition affect learning by invention? Instructional Science, 40, 711-730. https://doi.org/10.1007/s11251-012-9204-y.

Xiao, Y., \& Lucking, R. (2008). The impact of two types of peer assessment on students' performance and satisfaction within a Wiki environment. Internet and Higher Education, 11, 186-193. https://doi. org/10.1016/j.iheduc.2008.06.005.

Yamane, D. (1996). Collaboration and its discontents: Steps toward overcoming barriers to successful group projects. Teaching Sociology, 24, 378-383. https://doi.org/10.2307/1318875.

Yin, B., \& Chen, F. (2007). Towards automatic cognitive load measurement from speech analysis. In J. A. Jacko (Ed.), HCI 2007: Human-computer interaction Interaction design and usability (pp. 10111020). Berlin: Springer.

Zhang, L., Kalyuga, S., Lee, C., \& Lei, C. (2016). Effectiveness of collaborative learning of computer programming under different learning group formations according to students' prior knowledge: A cognitive load perspective. Journal of Interactive Learning Research, 27, 171-192.

Zheng, R. Z. (2018). Cognitive load measurement and application a theoretical framework for meaningful research and practice. London: Routledge.

Publisher's Note Springer Nature remains neutral with regard to jurisdictional claims in published maps and institutional affiliations.

Jeroen Janssen (1977) is Associate Professor of Educational Sciences at the Department of Education, Faculty of Social and Behavioural Sciences, Utrecht University, The Netherlands. His research interests include: (computer-supported) collaborative learning, educational technology, and self-regulated learning

Paul A. Kirschner (1951) is Professor Emeritus at the Open University of the Netherlands and is an Honorary Doctor (Doctor Honoris Causa) at the University of Oulu, Finland. Prior to his retirement he was Professor Distinguished University Professor and Professor of Educational Psychology at the Open University of the Netherlands and Visiting Professor of Education at the University of Oulu, Finland. 